\title{
Capability development by educational technology
}

\author{
Cedomir Gladovic \\ Holmesglen Institute
}

\begin{abstract}
The capability to identify and make a judgement about the quality of own and work of others is known as evaluative judgement. Such capability is crucial for learners and their learning trajectories, allowing them to become job-ready graduates and life-long learners. The overall concept is newly named but existed in different forms and shapes in the literature. There is sporadic literature investigation of evaluative judgement development by educational technology. Self-assessment, peer-assessment and portfolios in the online learning environment bring various educational values and benefits. Each of these pedagogical activities can contribute to the development of evaluative judgement in an online environment enhanced by educational technology. The primary purpose of this paper is to expand the discussion about the development of evaluative judgement using educational technology. This paper provides some rationale for the inclusion of selected pedagogical activities in the curriculum and actively using them in studentcentred education.
\end{abstract}

Keywords: Capability, evaluative judgement, self-assessment, peer-assessment, portfolio

\section{Introduction}

The concept of evaluative judgement is based on the notion of the capability to make decisions about the quality of work of self and others (Tai, Ajjawi, Boud, Dawson, \& Panadero, 2018). Evaluative judgement capability is crucial for learners, not only in terms of success in the educational environment but also in transforming them into life-long learners and preparing them for the professional world beyond education (Boud \& Soler, 2016). For a better understanding of evaluative judgement development, it is imperative that developmental concept, especially developmental concept in the online environment and by using educational technology, is analysed. It is unlikely that evaluative judgement will be developed before a suitable learning environment is created. Educational technology plays first and an essential role in creating a learning environment, which then becomes a driver for evaluative judgement development.

The identification of quality is an important concept in evaluative judgement but, as argued by Sadler (2013), is not something easily defined but recognised when seen. At least, it can be assumed that educational technology may help in making quality more 'visible' within the online learning environment. Therefore, quality within different pedagogical activities (i.e., self-assessment) should not be subject to a standardised process of identification, but educational technology can help educators and learners to identify and analyse the notion of quality. As an example, the learner may conduct the self-assessment exercise, which is then analysed and evaluated by an educator and feedback about achieved and expected quality provided back to a learner. In such a looping dialogical process, quality is not identified only in the artefact created by the learner (i.e., selfassessment), but also quality is also in a dialogical process between learner and educator, which occurred within the online learning environment. Such dialogue without educational technology can only occur in physical space where learner and educators are presented. However, educational technology allows learner and educators to have an asynchronous dialogue online and achieve the same if not even better and richer dialogue.

\section{Defining Evaluative Judgement}

Tai et al. (2018) define evaluative judgement as “... the capability to make decisions about the quality of work of self and others" (p. 5). Though newly named, the concept of evaluative judgement has existed in the literature for some time. Publication, 'Developing evaluative judgement in higher education' (Boud, Ajjawi, Dawson, \& Tai, 2018), extends the possibility to explore and evaluate the capability of evaluative judgement within the online educational environment. However, aside from this publication, there is limited literature investigating the development of evaluative judgement in the online environment and by educational technology.

Furthermore, little is known about the conscious and unconscious processes of the development of evaluative judgement. Yet another obstacle to better understanding evaluative judgement is our inability to define what the development of evaluative judgement in learners looks like in the online environment. 
Current understandings of evaluative judgement are closely structured around notions associated with the quality of the final product rather than around evaluating the quality of the overall process in which the quality has been achieved (Boud et al., 2018), in the physical or online learning environment. Operationalisation of evaluative judgement in terms of detecting how it is developed in the online environment is not well examined in the literature on education or educational technology. The concept of evaluative judgement has only recently been introduced as a desired life-long capability. However, within education and professional practices, we can identify evaluative judgement using quality as a proxy. For example, the quality of a completed house by a professional builder would not be evaluated simply by examining the final product rather through evaluating the level of adherence to building standards, within the agreed timeframe and budget. In the online educational environment, pedagogical activities such as self-assessment, peer-assessment, rubrics, exemplars and portfolio can be used as proxies to identify the development of evaluative judgement. For the context of this paper, selfassessment, peer-assessment and portfolio within online environment are examined to identify the development of evaluative judgement.

\section{Evaluative Judgement and Standards}

Standards play an essential role in the development of evaluative judgement and may be used as a good indicator of quality in the online environment. As evaluative judgement is developed within a specific context, standards provide a representation of such a context. The online educational environment allows standards to be represented clearly, transparently, and efficiently accessible by learners. Standards in this instance can be industry standard and practices or intended learning outcomes within a unit of learning. However, the existence and provision of such standards will not necessarily mean that learners will achieve a positive and quality outcome and guidance by educators is required. Apart from the guidance of educators, there needs to be some sort of validation that learners constructed knowledge and achieved required standards. This issue can be partly addressed when learners are provided with a 'road map', such as rubrics (Dawson, 2017). For learners to be able to use rubrics as drivers or guidelines towards understanding and achieving explicit learning outcomes, they need to develop capabilities such as evaluative judgement. Such a capability will help them to understand what constitutes acceptable or good work and to help them to develop a suitable execution strategy.

The dilemma of standards as a static concept is addressed by Ajjawi and Bearman (2018), who argue that standards are neither static nor a representation of absolute truth, but rather dynamic in its nature. Online educational environments support the dynamic and changing nature of standards as outdated and superseded standards can be promptly and effectively updated for learners (refers primarily to industry standards and processes). Furthermore, to use standards within the online environment, learners must use their skills and knowledge to calibrate their strategies for project execution once standards have been changed or updated. In other words, learners must be able to construct sufficient understanding and knowledge of the context in the right content to ensure achievement of standards.

To support this idea of dynamic concept in terms of standards, three distinctive cycles within online learning environment needs to be recognised: (i) assessment/professional standards, which describe what educators believe learners should achieve in the completion of a specific assessment, unit of learning or set of learning units; (ii) graduate attributes, which are a set of educational standards that are aligned with the standards inherent in learning units and must be achieved by all learners at the time of completion of their qualification; and (iii) professional industry standards, which are a set of professional standards and processes assumed to be achieved by learners upon the completion of their qualification. The transparency and explicitness of assessment standards drive the potential for learning improvement (Panadero \& Jonsson, 2013), as learners will be more focused on 'how to do it' rather than on 'what needs to be done'. Educational technology possesses the capacity to record and search for traces of evaluative judgement within the online learning environment and during the learning trajectories of learners.

\section{Identifying Evaluative Judgement through Online Pedagogical Activities}

Early notions of evaluative judgement can be traced back to Sadler (1989) idea of evaluative knowledge and expertise. There are traces of evaluative judgement in the literature that outlines its importance, but there is a limited amount of literature demonstrating development, growth, and maintenance of such capability. The underlying cause of such issues is a lack of theory and research around the concept of evaluative judgement (Tai et al., 2018). The operationalisation of evaluative judgement is explored in this paper through an analysis of online pedagogical activities such as self-assessment, peer-assessment, and portfolio. 


\section{Self-assessment}

Self-assessment requires learners to make a judgement about their own work against specific criteria (Adachi, Tai, \& Dawson, 2018). Boud, Lawson, and Thompson (2013) argue that such a process is a personal act but, at the same time, learners are prepared to be assessed by others at a later stage. Learners who are placed in this new role may find the new role and overall environment very challenging. Especially if and when the standards that need to be judged against self-assessment are not well defined. It is crucial to outline that self-assessment is not equivalent to evaluative judgements; however, they may share the same developmental path in the online environment. Self-assessment begins and ends its existence within a specific assessment or unit of learning. Furthermore, evaluative judgement is a capability that can be initiated via self-assessment but requires a more extended period of time to become capability. Continuity and consistent engagement in self-assessment exercises over a specified period of time may help learners to initiate their own evaluative judgement capability.

The repetition of self-assessment as an online pedagogical activity within the same unit of learning and horizontally and vertically across units of learning allows the learners to become more proficient in their learning. This view is also supported by Falchikov and Boud (1989), who argues that learners in their later years are better able to make judgements about their learning than in their early years. This may be the first piece of evidence regarding the development of evaluative judgement in the gradual learning process where selfassessment may serve as the crucial developmental driver. The development of evaluative judgement via selfassessment and in the online environment is not only evident in the final product only but also in the overall process. Evaluative judgement can be identified very early in the process of developing self-assessment. At the initiation of such a process, learners have to develop a strategy on how to self-assess themselves against specified learning outcomes. The next stage of the process would be for learners to rationalise how learning outcomes are achieved and identifiable in the final product (i.e., assessment task, report, essay). Within the process of identification, justification and evidence, learners make a judgement about the quality of the overall process as well as the final product. The online learning environment serves the purpose of 'a repository of evidence' for learners to record evidence of their learning. Consequentially, such record will contain constructs for development of evaluative judgement in the online environment.

Self-assessment as a driver towards the development of evaluative judgement also allows learners with every single iteration of self-assessment to develop a wide range of behavioural, cognitive, and transferable skills within the online environment. Such skills allow learners to construct knowledge and achieve required objectives in the most effective way. Apart from self-assessment as a driver for the development of evaluative judgement, time as an initiation factor needs to be added. If learners are making judgements about the quality of their own work against a specific set of standards and criteria over a more extended period, there is greater chance for development of evaluative judgement in the online environment.

\section{Peer-assessment}

Judging the work of others as an initial step in identifying what quality is and what constitutes quality within a specific context can help learners avoid biases when executing self-assessment (Dunning, Heath, \& Suls, 2004), as the focus shifts from themselves to others. Such an approach also helps learners develop the skill of being more proficient in making sound judgements about quality, which can then be transferred and applied as a judgement about the quality of their own work. Once learners can identify and evaluate the work of others against specific standards and criteria, such pedagogical engagement will contribute to the development of evaluative judgement through the identification of what constitutes the quality of others' work (Tai, Canny, Haines, \& Molloy, 2016).

The interaction between learners through the use of online peer-assessment as a pedagogical activity may contribute to the development of evaluative judgement (Nicol, Thomson, \& Breslin, 2014). During such online collaboration and even when the feedback is not received from educators, learners are not passive recipients of feedback but rather active learners and feedback providers. Another benefit of the online peer-assessment is the two-way learning opportunity it provides that is, the opportunity to provide constructive feedback and to receive and act upon the feedback provided. Such activity allows learners to see and compare quality produced by others against their own quality. The ability of a learner to evaluate the quality of their own work or the work of others is the first indication that the development of evaluative judgement in learners has been initiated. At the same time, the literature on professional education reports and confirms that pedagogical activities such as peer- 
assessment (among many others) contributes to development of evaluative judgement (Nicol et al., 2014; Tai et al., 2018; Tai et al., 2016); however, it is unclear under which circumstances this occurs.

Similar to self-assessment, peer-assessment assists with the development of evaluative judgement throughout the whole learning process and not only at the stage when the final product is evident. During the peerassessment process, learners are not only able to analyse the work of others, but they are also able to make a judgement about quality. During such a process, they are also able to compare the quality of their own work against the quality of their peers' work and, consequently, calibrate their own work. The ability of a learner to identify quality and calibrate their own work is characteristic of evaluative judgement.

\section{Reflective Portfolio}

Reflective portfolio within the educational and professional environment can be defined as the collected evidence that learning occurred (Challis, 1999). Within some professions, such as architecture, it is common practice to collect evidence of learning, capabilities, and outcomes in the form of the portfolio for different parties. Within the educational sector, the purpose of the portfolio is; (i) to increase a learner's self-awareness, (ii) to increase the possibility to learn independently, and (iii) to encourage learners to reflect on their performances (Buckley et al., 2009). Reference to reflective practice of learners appears to be a suitable starting point in research for the investigation of the possibility of development of evaluative judgement in the online environment. From another perspective, Buckley et al. (2009) also reflected on the importance of time, which needs to be allocated to learners to allow reflective skills to develop. This notion of time with respect to the development of reflective practice is a positive movement towards a better understanding that capabilities such as reflective practices and evaluative judgement require the allocation of a certain time period. Portfolio is one of the pedagogical activities that can be used to encourage learners to reflect on their experiences and achievements and record it in the online environment.

Portfolio activities enable learners to document their achievements and their reflections at different points of time throughout specific assessment tasks, across multiple assessment tasks within a unit of learning or across multiple units of learning. This is a great opportunity for educators to support the online learning processes and help learners to move from one stage of their learning to another. Educators can also use the same process to identify and further assist learners who require additional support. The portfolio should not simply be a collection of selected works online but rather extended as a reflective online dialogue between learners and educators. The development and operationalisation of evaluative judgement via portfolio activities appear to be more complex to observe due to their unique purpose. Characteristically, portfolio is collected evidence that learning occurred, but the processes behind how such learning occurred are not always explicit. The decision by learners about what to include in the portfolio and what to exclude through the use of quality may be seen as an indicator of evaluative judgement within this online pedagogical activity.

\section{How can Technology Facilitate Developmental Process of Evaluative Judgement?}

In today's higher education environment, technology is embedded not only as supporting parameter for learning but rather as an integrated curriculum ingredient. For an extended period, educational technology has a vital role in facilitating learning, especially distant education. Educational technology provides revenue to implement selfassessment, peer-assessment, and portfolios successfully into the online learning environment. By such implementation, these pedagogical activities will serve more extended purposes. For example, Learning Management Systems (LMS's) provides a suitable and sufficient medium for learners to share their work, to have dialogical feedback with their peers and educators and to create evidence of learning in an online environment. The other main benefit of educational technology is to allow these pedagogical activities to be used as references for learners to construct their knowledge beyond a single unit of learning. For example, learners can create a portfolio at the beginning of their educational journey and regularly document their learning progress across multiple units of learning and course of study. Similar longevity of self and peerassessments can be provided for learners to have a reference point of their work and to use it to calibrate the quality of their future works.

At the same time, the implementation of these pedagogical activities within online learning environments may foster the development of evaluative judgement. Some key components of evaluative judgement such as time allocation for development, easy access to relevant standards, criteria among many others, require the support of 
learning technology. Evaluative judgement is complex and continually developing capability, but more transparency is required to understand its developmental processes better. Such transparency can be offered by educational technology. Therefore, it is imperative to use educational technology to create longitudinal evidence of evaluative judgement development in the online environment as a repository of learners' understanding of quality. Self-assessment, peer-assessment and portfolios are more likely to contribute to the development of evaluative judgement. Consequently, the evaluative judgement will enhance and extended purposes and values of self-assessment, peer-assessment, and portfolio. Overall, an evaluative judgement is a very complex but at the same time fascinating educational and professional capability which transform learners into active participants and at later stage industry professionals. In such a developmental process, educational technology plays a significant developmental role.

\section{References}

Adachi, C., Tai, J., \& Dawson, P. (2018). Academics' perceptions of the benefits and challenges of self and peer assessment in higher education. Assessment \& Evaluation in Higher Education, 43(2), 294-306. https://doi.org/10.1080/02602938.2017.1339775

Ajjawi, R., \& Bearman, M. (2018). Problematising standards: representation or performance? In D. Boud, R. Ajjawi, P. Dawson, \& J. Tai (Eds.), Developing evaluative judgement in higher education: assessment for knowing and producing quality work. Oxon: Routledge. https://doi.org/10.4324/9781315109251-5

Boud, D., Ajjawi, R., Dawson, P., \& Tai, J. (2018). Developing evaluative judgement in higher education: assessment for knowing and producing quality work. Oxon: Routledge. https://doi.org/10.4324/9781315109251

Boud, D., Lawson, R., \& Thompson, D. G. (2013). Does student engagement in self-assessment calibrate their judgement over time? Assessment \& Evaluation in Higher Education, 38(8), 941-956. https://doi.org/10.1080/02602938.2013.769198

Boud, D., \& Soler, R. (2016). Sustainable assessment revisited. Assessment \& Evaluation in Higher Education, 41(3), 400-413. https://doi.org/10.1080/02602938.2015.1018133

Buckley, S., Coleman, J., Davison, I., Khan, K. S., Zamora, J., Malick, S., . . Sayers, J. (2009). The educational effects of portfolios on undergraduate student learning: a Best Evidence Medical Education (BEME) systematic review. BEME Guide No. 11. Medical Teacher, 31(4), 282-298. https://doi.org/10.1080/01421590902889897

Challis, M. (1999). AMEE Medical Education Guide No. 11 (revised): portfolio-based learning and assessment in medical education. Medical Teacher, 21(4), 370-386. https://doi.org/10.1080/01421599979310

Dawson, P. (2017). Assessment rubrics: towards clearer and more replicable design, research and practice. Assessment \& Evaluation in Higher Education, 42(3), 347-360.

https://doi.org/10.1080/02602938.2015.1111294

Dunning, D., Heath, C., \& Suls, J. M. (2004). Flawed self-assessment implications for health, education, and the workplace. Psychological Science in the Public Interest, Supplement, 5(3), 69-106. https://doi.org/10.1111/j.1529-1006.2004.00018.x

Falchikov, N., \& Boud, D. (1989). Student Self-Assessment in Higher Education: A Meta-Analysis. Review of Educational Research, 59(4), 395-430. https://doi.org/10.2307/1170205

Nicol, D., Thomson, A., \& Breslin, C. (2014). Rethinking feedback practices in higher education: a peer review perspective. Assessment \& Evaluation in Higher Education, 39(1), 102-122. https://doi.org/10.1080/02602938.2013.795518

Panadero, E., \& Jonsson, A. (2013). The use of scoring rubrics for formative assessment purposes revisited: A review. Educational Research Review, 9(0), 129-144. https://doi.org/10.1016/j.edurev.2013.01.002

Sadler, D. R. (1989). Formative assessment and the design of instructional systems. Instructional Science, 18(2), 119-144. https://doi.org/10.1007/BF00117714

Sadler, D. R. (2013). Assuring academic achievement standards: from moderation to calibration. Assessment in Education: Principles, Policy \& Practice, 20(1), 5-19. https://doi.org/10.1080/0969594X.2012.714742

Tai, J., Ajjawi, R., Boud, D., Dawson, P., \& Panadero, E. (2018). Developing evaluative judgement: enabling students to make decisions about the quality of work. Higher Education, 76(3), 467-481. https://doi.org/10.1007/s10734-017-0220-3

Tai, J., Canny, B. J., Haines, T. P., \& Molloy, E. K. (2016). The role of peer-assisted learning in building evaluative judgement: opportunities in clinical medical education. Advances in Health Sciences Education, 21(3), 659-676. https://doi.org/10.1007/s10459-015-9659-0 
Gladovic, C. (2021). Capability development by educational technology. In Gregory, S., Warburton, S., \& Schier, M. (Eds.), Back to the Future - ASCILITE '21. Proceedings ASCILITE 2021 in Armidale (pp. 143-148). https://doi.org/10.14742/ascilite2021.0119

Note: All published papers are refereed, having undergone a double-blind peer-review process.

The author(s) assign a Creative Commons by attribution licence enabling others to distribute, remix, tweak, and build upon their work, even commercially, as long as credit is given to the author(s) for the original creation.

(c) Gladovic, C. 2021 